Jpn. J. Med. Mycol.

Vol. 21, 230-238, 1980

ISSN $0583-0516$

\title{
The Serological, Chemical and Physicochemical Analyses of Cryptococcal Capsular Polysaccharides
}

\author{
Takako Shinoda*, Reiko Ikeda, Akemi Nishikawa and \\ Yoshimura Fukazawa** \\ Department of Microbiology, Meiji College of Pharmacy, Tanashi, Tokyo 188, Japan and \\ **Department of Microbiology, Medical University of Yamanashi, Nakakoma-gun, \\ Yamanashi 409, Japan
}

[Received for Publication: August 4, 1980]

\begin{abstract}
The taxonomic value of cryptococcal capsular polysaccharides was studied by comparing those of Cryptococcus neoformans and of nine related species. The characterization of the soluble capsular polysaccharides of these 10 species by their serological specificity, chemical constituents and structures represented by the proton magnetic resonance (PMR) spectra demonstrated a division into 2 groups. Species belonging to one group were closely related to $C$. neoformans and the members of the other group were markedly different from those of the former. It is suggested that the serological, chemical and physicochemical properties of capsular polysaccharides would be useful criteria for the classification of the Cryptococcus species.
\end{abstract}

Tsuchiya et $a l .^{1,2)}$ carried out antigenic analyses of various species of yeasts and a new system for yeast classification was proposed. The significance of the proton magnetic resonance (PMR) spectra of the yeast alkali-extracted polysaccharides for taxonomic studies and the correlation between PMR spectra and chemical structures of some yeast species have been investigated and summerized by Gorin and Spencer ${ }^{3)}$. They reported that in many instances the PMR spectral types of yeast strains correlated well with the serological types established by Tsuchiya et al. Recently chemical and physicochemical characteristics of the polysaccharides have been recognized as one of the important criteria in yeast taxonomy.

Cryptococcus neoformans is one of the clinically important yeast-like fungi. Among Cryptococcus species, however, because of poor antigenicity and

\footnotetext{
*To whom inquires should be addressed.
}

the viscosity of polysaccharide solutions, antigenic and physicochemical analyses of their polysaccharides have not been well developed to date.

The purpose of this paper is to show the differences among Cryptococcus species based upon their serological, chemical and physicochemical characteristics, including the PMR spectra of their polysaccharides, and to evaluate those properties as criteria for the classification of the Cryptococcus species.

\section{MATERIALS AND METHODS}

Cultures. Eight strains of Cryptococcus and two Candida species, which have been shown to be closely related to Cryptococcus species serologically and also have minor capsule, were used for the serological and chemical studies. The strains are listed in Table 1.

Physiological characteristics. Physiological characteristics were examined by sugar assimila- 
tion and urease tests. The assimilation tests were performed by the use of the 12 sugars in the Minitek identification kit for yeasts (Baltimore Biological Laboratories). Urease reactions were determined by the methods of Seeliger ${ }^{4)}$.

Antiserum. Antisera to $C$. neoformans and the other species were prepared as follows: Heatkilled cells were suspended in physiological saline solution (PSS) at $4^{\circ} \mathrm{C}$. A solution of 2,4,6trichloro-s-treazine in dimethyl formamide was then added to the cooled solution. The reaction was stirred at $4^{\circ} \mathrm{C}$ for $1 \mathrm{~h}$ before addition of a solution of bovine $\gamma$-globulin (BGG) in PSS. The mixture was then stirred at $25^{\circ} \mathrm{C}$ for $1 \mathrm{~h}$, kept at $4^{\circ} \mathrm{C}$ for $18 \mathrm{~h}$, and dialyzed against distilled water for $30 \mathrm{~h}$. Rabbits were immunized with cell-BGG conjugate suspended in formalinized saline solution at a concentration equivalent to $3.8 \times 10^{7} \mathrm{cells} / \mathrm{ml}$. Rabbits were given intravenous injections with the cell-BGG conjugate of $0.5,1.0,2.0,4.0,4.0$ and $4.0 \mathrm{ml}$ at 4 -day intervals. The injected rabbits were bled from the marginal veins of their ears and the sera tested for their agglutination titers against the homologous organisms. When the titer of a given antiserum was 1:640 or higher, the rabbits were bled seven days after the last injection. In cases where their titer did not reach the desired level, injections of $4.0 \mathrm{ml}$ of antigen were continued until the desired titer was obtained.

Serological characteristics. The serological characteristics of the strains were examined by tube agglutination tests, passive haemagglutination $(\mathrm{PHA})^{5)}$ tests and precipitin reactions. Precipitin reactions between antiserum and polysaccharide were performed in PSS with $0.1 \mathrm{ml}$ of serum in a final volume of $1.0 \mathrm{ml}$. Incubation was at $4^{\circ} \mathrm{C}$ for $48 \mathrm{~h}$. The precipitate was washed twice with cold PSS by centrifugation. Precipitated antibody protein was measured by the method of Lowry et al. ${ }^{6)}$

Isolation and purification of soluble polysaccharide. To obtain soluble polysaccharide, each strain was grown in yeast nitrogen base broth (Difco) containing 2\% glucose, 1\% casamino acids and $100 \mu \mathrm{g} / \mathrm{ml}$ streptomycin at $27^{\circ} \mathrm{C}$ for 5 days with shaking. The broth culture was sterilized at $100^{\circ} \mathrm{C}$ for 20 minutes standing in flowing steam and the supernatant was separated by centrifugation. After concentration and dialysis of the supernatant, 9 volumes of ethanol and $1 / 10$ volume of $10 \%$ sodium acetate solution were added. The precipitate was dissolved in water, dialyzed against water and lyophilized. Crude polysaccharide was treated with pronase by the method of Kozel et al. ${ }^{5)}$ Total carbohydrate was determined by the phenol-sulfuric acid $\operatorname{method}^{7)}$, and total protein was determined by the method of Lowry et $a l^{6)}$.

Chemical analysis of polysaccharide. The conditions for acid hydrolysis were similar to those used by Gorin and Spencer ${ }^{8}$. About $5 \mathrm{mg}$ of polysaccharide were dissolved in $2 \mathrm{ml}$ of $1 \mathrm{~N}$ $\mathrm{H}_{2} \mathrm{SO}_{4}$, heated in a sealed glass tube at $100^{\circ} \mathrm{C}$ for $18 \mathrm{~h}$ and neutralized with $\mathrm{BaCO}_{3}$. The hydrolysate was then evaporated to syrup. Thin layer chromatography and gas liquid chromatography were used to identify the constituent carbohydrates of the polysaccharides. The solvent system used for thin layer chromatography consisted of $\mathrm{n}$-butanol, ethanol and water at a $\mathrm{v} / \mathrm{v}$ ratio of 40,11 , and 19 . Spots were detected with $\mathrm{p}$-anisidine spray reagent. The hydrolyzate was converted into alditol acetates and analyzed quantitatively by gas liquid chromatography. The procedure was as follows: The hydrolyzate was reduced with sodium borohydride for $3 \mathrm{~h}$ at room temperature. Excess borohydride was destroyed by addition of Amberlite IR-120 $\left(\mathrm{H}^{+}\right.$ form), and the solution was evaporated to dryness. Methanol was added to the product, and evaporated to dryness repeatedly. Equal amounts of acetic anhydride and pyridine were added and kept at $100^{\circ} \mathrm{C}$ for $2 \mathrm{~h}$. Water was added to the cooled reaction mixture, and evaporated to syrup. The residue was dissolved in chloroform and injected into the gas chromatograph. Gas liquid chromatography was carried out by a Shimadzu Gas Chromatograph GC-6A (Shimadzu Seisakusho Ltd. Tokyo) using a glass column containing $3 \%$ of ECNSS-M on Gas Chrom Q at $190^{\circ} \mathrm{C}$. The uronic acid content of the soluble polysaccharide were determined by the carbazole $\operatorname{method}^{9)}$.

Determination of PMR spectrum of polysaccharide. The PMR spectra were deter- 
mined with $1 \%$ solutions of polysaccharide in deuterium oxide at $80^{\circ} \mathrm{C}$ with a Bruker WH$270 \mathrm{MHz}$ nuclear magnetic resonance spectrometer in which sodium 3-trimethylsirylpropionate (TSP) was employed as the internal standard.

\section{RESULTS}

Physiological characteristics. The assimilation patterns of the 12 carbohydrates and hydrolysis of urea by a strain of $C$. neoformans and 9 strains of the related species are shown in Table 1. The characteristics of these strains agreed quite well with their standard descriptions as published in "The Yeasts"10). All strains hydrolyzed urea.

Serological characteristics. To determine the serological relationships among the species, the antibody activities of the anti- $C$. neoformans serum were tested against homologous cells and the cells of other species (Fig. 1). In the direct agglutination tests, the antigens of $C$. neoformans, $C$. terreus, C. albidus var. diffluens, $C$. albidus var. albidus, Candida curvata and $C$. humicola reacted very closely, but $C$. luteolus, $C$. gastricus, $C$. laurentii var. laurentii and $C$. uniguttulatus reacted weakly with the anti-C. neoformans serum. The cross- reactivity patterns obtained by PHA paralleled those obtained by direct agglutinations. Similarly, in the quantitative precipitation tests of the poly-

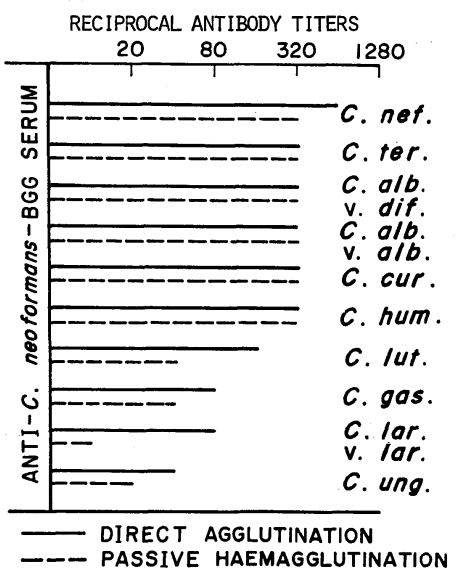

Fig. 1. Cross agglutination patterns of Cryptococcus neoformans and related species against anti-C. neoformans-BGG serum.

C. nef., C. neoformans; C. ter., C. terreus; C. alb. var. dif., $C$. albidus variety diffluens; $C$. alb. var. alb., $C$. albidus variety albidus; $C$. cur., Candida curvata; $C$. hum., Candida humicola; C. lut., C. luteolus; C. gas., C. gastricus; C. lar. var. lar., C. laurentii variety laurentii; C. ung., C. uniguttulatus.

Table 1. Assimilation of carbohydrates and hydrolysis of urea by Cryptococcus neoformans and related species

\begin{tabular}{|c|c|c|c|c|c|c|c|c|c|c|c|c|c|c|c|}
\hline \multirow{2}{*}{\multicolumn{3}{|c|}{ Strains studied }} & \multicolumn{12}{|c|}{ Assimilation of: } & \multirow{3}{*}{$\begin{array}{c}\text { Hydrolysis } \\
\text { of } \\
\text { urea }\end{array}$} \\
\hline & & & \multirow{2}{*}{$\begin{array}{l}u \\
o \\
0 \\
\vdots \\
\\
0 \\
+\end{array}$} & \multirow{2}{*}{ 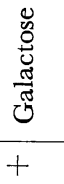 } & \multirow{2}{*}{ 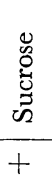 } & \multirow{2}{*}{ 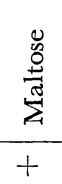 } & \multirow{2}{*}{ 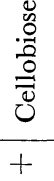 } & \multirow{2}{*}{ 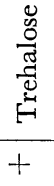 } & \multirow{2}{*}{ 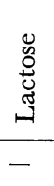 } & \multirow{2}{*}{ 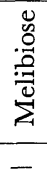 } & \multirow{2}{*}{ 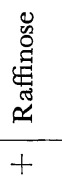 } & \multirow{2}{*}{ 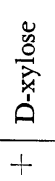 } & \multirow{2}{*}{ 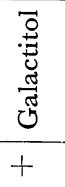 } & \multirow{2}{*}{ 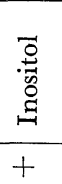 } & \\
\hline C. neoformans & CBS & 132 & & & & & & & & & & & & & \\
\hline C. terreus & IFO & 0717 & + & $+{ }^{b}{ }_{\mathrm{w}}$ & - & + & + & $t_{w}$ & $t_{w}$ & - & - & + & $t_{w}$ & $t_{w}$ & + \\
\hline $\begin{array}{l}\text { C. albidus } \\
\quad \text { var. albidus }\end{array}$ & CBS & 142 & + & $t_{w}$ & + & + & + & + & + & - & $t_{w}$ & + & $+_{w}$ & + & + \\
\hline $\begin{array}{l}\text { C. albidus } \\
\quad \text { var. diffluens }\end{array}$ & CBS & 160 & + & - & + & + & $+_{w}$ & + & - & - & $+_{w}$ & + & + & $+_{w}$ & + \\
\hline C. curvata ${ }^{a}$ & CBS & 570 & + & + & + & $t_{w}$ & + & + & + & - & + & + & - & $t_{w}$ & + \\
\hline C. humicola $a$ & CBS & 571 & + & $+_{w}$ & + & + & + & + & + & + & $t_{w}$ & + & + & + & + \\
\hline C. luteolus & CBS & 943 & + & + & + & + & + & + & - & + & + & + & $+_{w}$ & + & + \\
\hline C. gastricus & CBS & 1927 & + & + & - & + & + & + & - & - & - & + & - & + & + \\
\hline $\begin{array}{l}\text { C. laurentii } \\
\quad \text { var. laurentii }\end{array}$ & CBS & 139 & + & + & + & + & + & $t_{w}$ & + & + & + & + & $+_{w}$ & + & + \\
\hline C. uniguttulatus & CBS & 1730 & + & - & + & + & - & + & - & - & - & + & - & + & + \\
\hline
\end{tabular}

a Candida species

$b$ weakly positive 


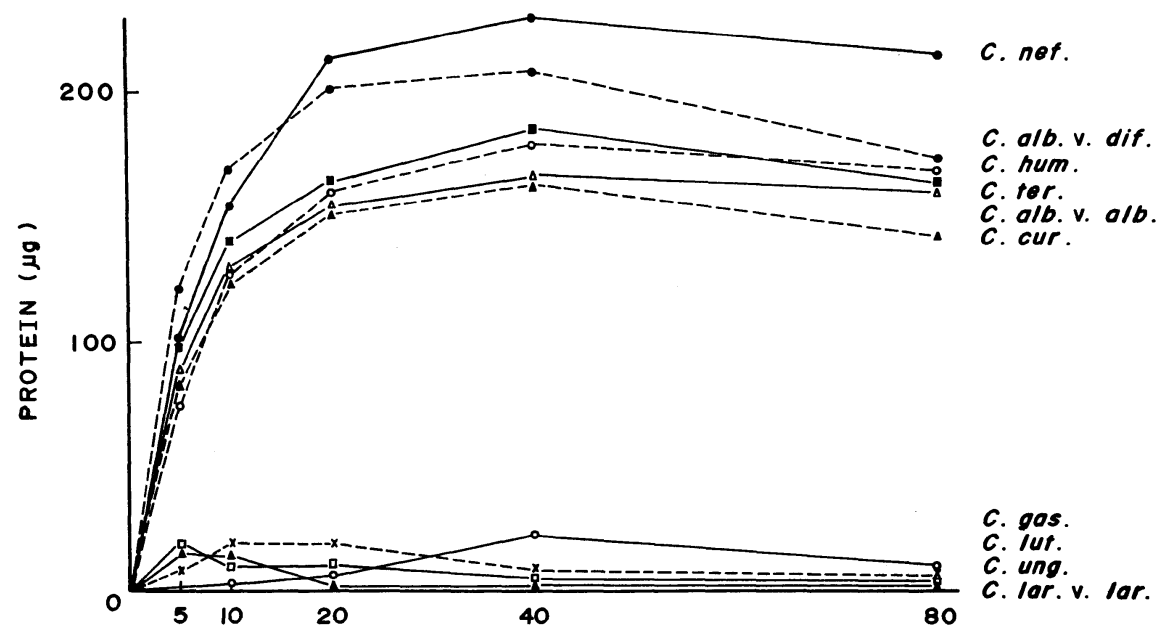

POLYSACCHARIDE ( $\mu$ )

Fig. 2. Precipitin curves of anti-C. neoformans-BGG serum against pclysaccharides of Cryptococcus neoformans and related species.

Symbols; -——, C. neoformans; ๑--- , C. albidus variety diffluens; O--- O, Candida humicola; $\mathbf{-}-C$. terreus; $\Delta-\Delta, C$. albidus variety albidus; $\mathbf{\Delta - \Delta}$, Candida curvata; $0-0, C$.

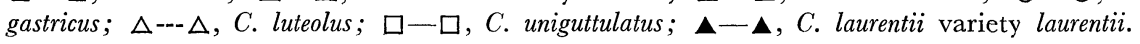

Table 2. Molar ratios of sugar components of polysaccharides of $C$. neoformans and related species

\begin{tabular}{|c|c|c|c|c|c|c|}
\hline \multirow{2}{*}{\multicolumn{2}{|c|}{ Polysaccharides from }} & \multicolumn{5}{|c|}{ Molar ratios of sugar components } \\
\hline & & \multirow{2}{*}{$\frac{\text { Man }}{3.3}$} & \multirow{2}{*}{$\begin{array}{l}\mathrm{Xyl} \\
1.0\end{array}$} & \multirow{2}{*}{$\begin{array}{c}\text { Gal } \\
0.5\end{array}$} & \multirow{2}{*}{$\frac{\text { Glc }}{-}$} & \multirow{2}{*}{$\frac{\text { SlcUA }^{a}}{1.6}$} \\
\hline C. neoformans & CBS 132 & & & & & \\
\hline C. terreus & IFO 0717 & 1.5 & 1.0 & 0.6 & - & 0.6 \\
\hline C. albidus var. albidus & CBS 142 & 2.0 & 1.0 & 0.7 & - & 0.9 \\
\hline C. albidus var. diffluens & CBS 160 & 2.1 & 1.0 & - & - & 0.8 \\
\hline C. curvatab & CBS $\quad 570$ & 2.3 & 1.0 & - & - & 0.8 \\
\hline C. humicolab & CBS 571 & 2.0 & 1.0 & - & - & 0.6 \\
\hline C. luteolus & CBS 943 & 5.3 & 1.0 & - & - & 3.1 \\
\hline C. gastricus & CBS 1927 & 0.6 & 1.0 & - & - & 0.3 \\
\hline C. laurentii var. laurentii & CBS 139 & 2.9 & 1.0 & 1.9 & 0.9 & 1.4 \\
\hline C. uniguttulatus & CBS 1730 & 4.0 & 1.0 & 2.2 & 0.5 & 0.9 \\
\hline
\end{tabular}

a Man, mannose; Xyl, xylose; Gal, galactose; Glc, glucose; ClcUA, glucuronic acid

$b \quad$ Candida species

saccharides of $C$. neoformans and other species against anti-C. neoformans serum, the polysaccharides from species, which demonstrated strong cross-reactions against anti-C. neoformans serum in direct agglutination, precipitated but the other polysaccharides did not precipitate (Fig. 2). These results indicated that the Cryptococcus species could be divided into two groups based on their serological reactivity against the anti-C. neoformans serum.

Chemical analysis of soluble polysaccharides. Purified polysaccharides from all species tested contained total protein of less than $1.9 \%$. The qualitative and quantitative analyses of constituent monosaccharides were determined by thin layer and gas liquid chromatography. 


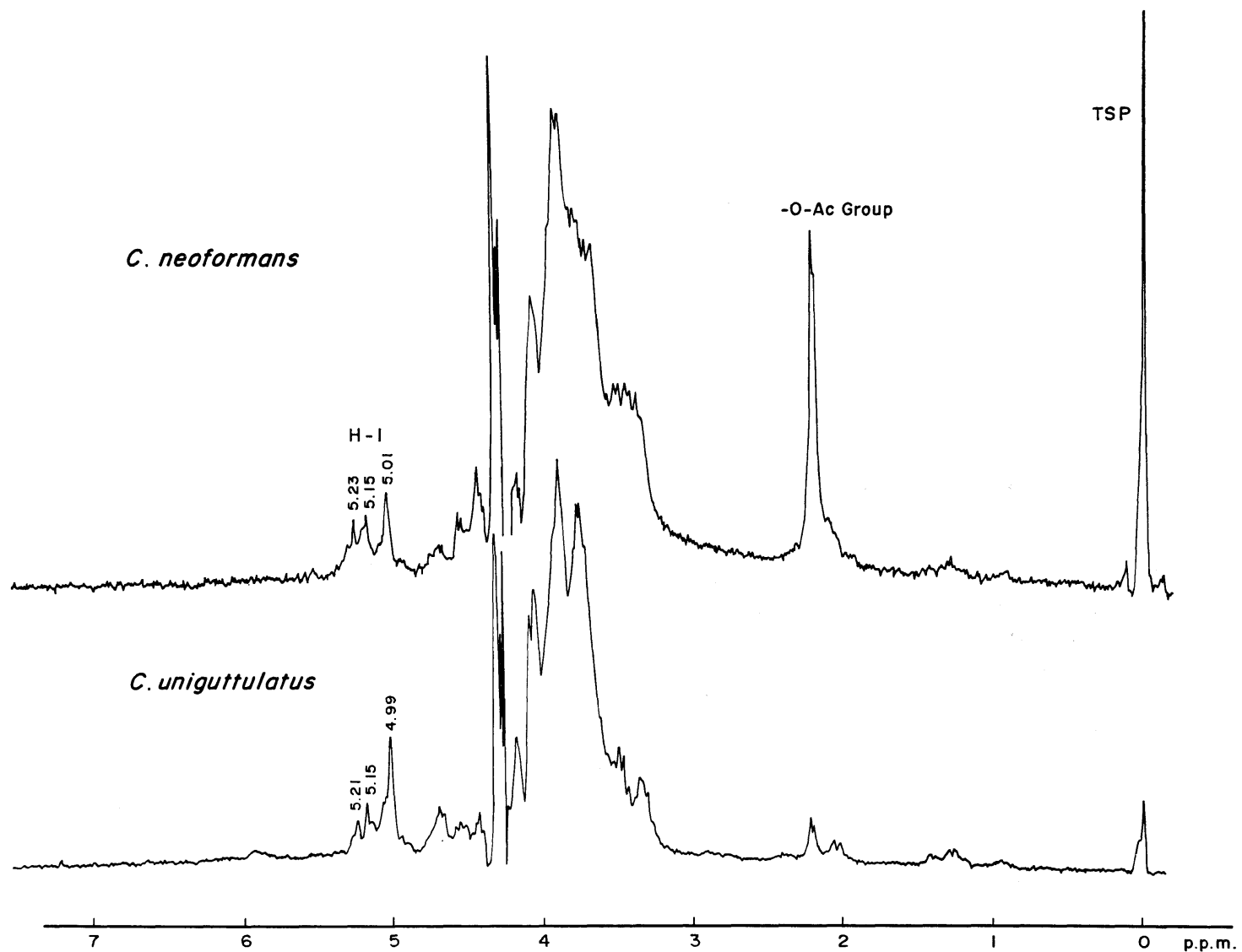

Fig. 3. PMR spectra of polysaccharides of C. neoformans and C. uniguttulatus in $\mathrm{D}_{2} \mathrm{O}$ at $80^{\circ} \mathrm{C}$. Arabic numerals indicate chemical shifts of each signal. H-1, H-1 region; -O-Ac, -O-acetyl; TSP, sodium 3trimethylsirylpropionate.

As shown in Table 2, the compositions of the polysaccharides from $C$. neoformans and the following five species, which were closely related to $C$. neoformans serologically, were shown to be of similar in composition of monosaccharides, except for their galactose content. As to the other four strains the patterns of carbohydrate contents were characteristic for each species. The polysaccharide from $C$. luteolus contained a lot of mannose and glucuronic acid, and the polysaccharide from C. gastricus contained a smaller amount of those monosaccharides relatively. The last two polysaccharides obtained from $C$. laurentii var. laurentii and $C$. uniguttulatus were shown to have a similar composition of monosaccharides.

PMR spectra of polysaccharides. The PMR spectra at $270 \mathrm{MHz}$ of polysaccharides from
C. neoformans and $C$. uniguttulatus are shown in Fig. 3. As mentioned above, both species were clearly divided into different serological groups. The $\mathrm{H}-1$ region of both polysaccharides demonstrated 3 main signals at 5.01 and $4.99 \mathrm{ppm}, 5.15$ ppm, 5.23 and $5.21 \mathrm{ppm}$ respectively, showing that only the intensity of the signal at $4.99 \mathrm{ppm}$ differed markedly between the two strains. Further, while the PMR spectrum of the polysaccharide from $C$. neoformans showed a characteristic signal at $2.19 \mathrm{ppm}$, thus showing the presence of O-acetyl groups, the polysaccharide from $C$. uniguttulatus gave only a very small signal in this field. The signals of the $\mathrm{H}-1$ region of PMR spectra of the polysaccharides from all of the species are shown in Table 3 and Fig. 4. The relative intensity of the signals at $2.2 \mathrm{ppm}$ 
Table 3. PMR signals from the polysaccharides of Cryptococcus neoformans and related species

\begin{tabular}{|c|c|c|c|c|c|c|c|c|c|c|}
\hline \multicolumn{3}{|c|}{ Strains studied } & \multicolumn{7}{|c|}{ Signal (ppm) } & \multirow{2}{*}{$\begin{array}{c}\begin{array}{c}\text { Relative } \\
\text { intensity } \\
\text { of } 2.2 \mathrm{ppm}^{b}\end{array} \\
\mathrm{~S} c\end{array}$} \\
\hline C. neoformans & CBS & 132 & 5.01 & & 5.15 & 5.17 & 5.23 & & & \\
\hline C. terreus & IFO & 0717 & 4.98 & & 5.13 & 5.18 & 5.23 & & & $\mathbf{M}$ \\
\hline $\begin{array}{l}\text { C. albidus } \\
\text { var. albidus }\end{array}$ & CBS & 142 & 4.99 & & 5.14 & 5.19 & 5.22 & & & $\mathrm{~S}$ \\
\hline C. curvata ${ }^{a}$ & CBS & 570 & 4.98 & & 5.15 & & 5.24 & & & $\mathrm{~S}$ \\
\hline $\begin{array}{l}\text { C. albidus } \\
\quad \text { var. diffluens }\end{array}$ & CBS & 160 & 5.00 & 5.06 & & & 5.26 & & & $\mathrm{~S}$ \\
\hline C. humicola $a$ & CBS & 571 & & 5.08 & & & 5.25 & & & $\mathrm{~S}$ \\
\hline C. luteolus & CBS & 943 & & & & & 5.23 & & & $\mathbf{M}$ \\
\hline C. gastricus & CBS & 1927 & 5.00 & 5.05 & 5.14 & 5.18 & 5.22 & 5.28 & 5.32 & $\mathrm{~W}$ \\
\hline $\begin{array}{l}\text { C. laurentii } \\
\text { var. laurentii }\end{array}$ & CBS & 139 & 4.99 & & & 5.18 & 5.23 & & 5.36 & $\mathrm{~W}$ \\
\hline C. uniguttulatus & CBS & 1730 & 4.99 & & 5.15 & & 5.21 & & & $\mathrm{~W}$ \\
\hline
\end{tabular}

a Candida species

$b$ peak at $2.2 \mathrm{ppm}$ is due to O-acetyl group

c S: strong, $\mathrm{M}$ : intermediate, $\mathrm{W}$ : weak

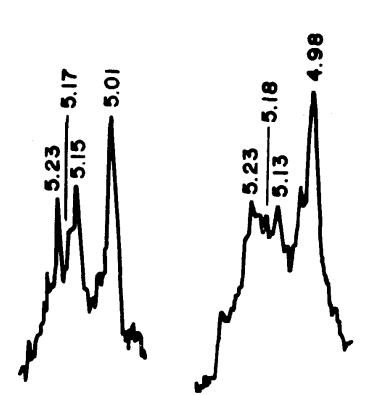

C. nef.

C. ter.

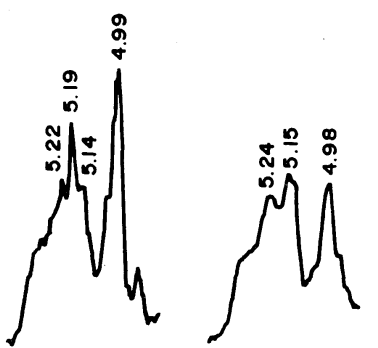

c. alb. vor. alb.

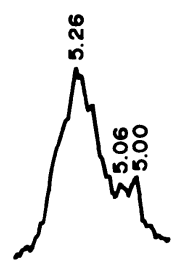
c. alb.

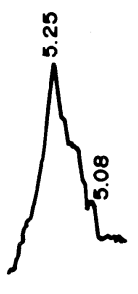

c. num.

B

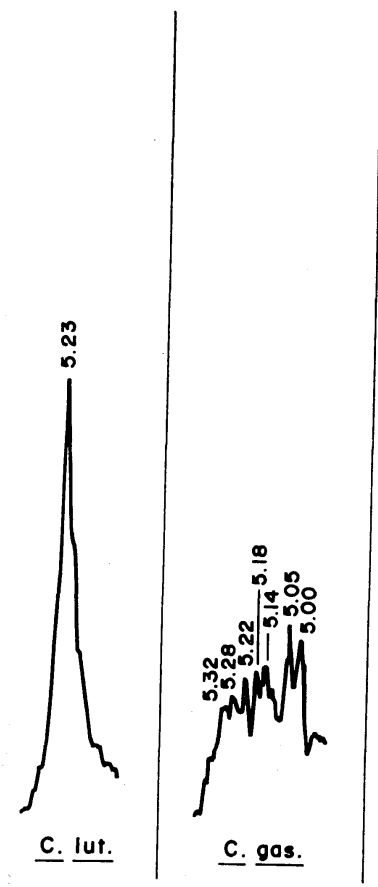

D

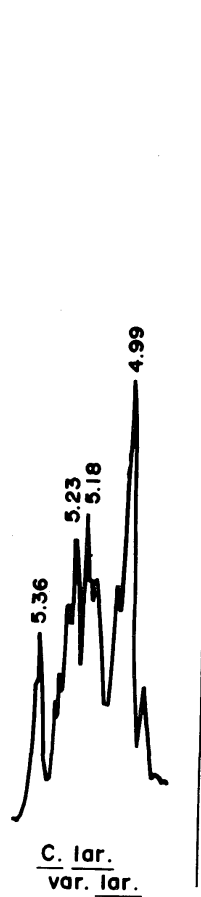

E

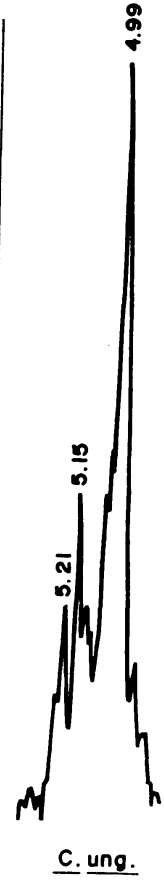

F

Fig. 4. PMR spectra (H-1 region) of polysaccharides of $C$. neoformans and related species in $\mathrm{D}_{2} \mathrm{O}$ at $80^{\circ} \mathrm{C}$. Arabic numerals indicate chemical shifts of each signal. 
are shown in Table 3 . The 6 serologically related species were further divided into two subgroups based on the spectral patterns of their $\mathrm{H}-1$ regions. One group consisted of $C$. neoformans, $C$. terreus, $C$. albidus var. diffluens, and Candida curvata, and the other one consisted of C. albidus var. albidus and Candida humicola. The other four species, that reacted weakly with the anti-C. neoformans serum, showed characteristic spectra for each species. The intensity of the signals at $2.2 \mathrm{ppm}$ that showed the presence of O-acetyl groups were observed to be fairly parallel to the serotypes.

\section{DISGUSSION}

Recently the chemical structures of the antigenic determinants of Saccharomyces cerevisiae and a few Candida species have been defined by Fukazawa et al. ${ }^{11)}$ The experiments on the serological relationship among Cryptococcus species, obtained either by agglutination or by quantitative precipitation, showed that these species could be divided into two groups based on their reactivity against anti-C. neoformans serum, although antisera of the other group's species could not be obtained. In contrast to the cell-BGG conjugate of $C$ neoformans ${ }^{12)}$, the cell-BGG conjugate and the polysaccharide-BGG conjugate of the species of the other group failed to induce antibody. The reason for the lower immunogenicity of the conjugate of the species is not clear at present. The polysaccharide components of six strains, which were closely related to $C$. neoformans serologically, resembled each other qualitatively and quantitatively. On the other hand, the strains of the other four species, that showed only weak cross-reactivities to $C$. neoformans serologically, showed characteristic patterns for each species. These results, as well as the results obtained by PMR spectra, suggested that the chemical constituents and structures of the polysaccharides of the Cryptococcus species are closely related to their serological characteristics. We have not demonstrated that the polysaccharides from the nine species, other than $C$. neoformans, are a single entity, but they were obtained by the same method as the $C$. neoformans polysaccharide which eluted as a single peak on a SG-200 Gel filtration column and as one peak in analytical ultracentrifugation.
As to the Cryptococcus species, because of their poor antigenicity and the viscosity of their polysaccharide solutions, antigenic and physicochemical analysis have not been developed as yet. Since the inperfect states of the Cryptococcus species have only poor morphological and physiological features, their capsular polysaccharides should be expected to be of significant taxonomic value.

Although the PMR spectra of mannose containing polysaccharides are known to be useful for yeast classification, PMR analysis of the polysaccharides of the Cryptococcus strains was very difficult because of the viscosity of their solutions ${ }^{3)}$. In the present study, however, we succeeded in getting their spectra through the use of soluble polysaccharides and also by the use of a $270 \mathrm{MHz}$ nuclear magnetic resonance spectrometer. In the study of the PMR spectra of the polysaccharides of the Cryptococcus species, we found Oacetyl groups in the spectra in addition to the characteristic spectrum in the $\mathrm{H}-1$ region. We also found that the amount of O-acetyl groups correlated with serological specificity. Therefore it is suggested that the O-acetyl groups would be one of the important chemical constituents for antigenic determinant.

In 1961, Miyazaki proposed the chemical structures of a repeating unit of capsular polysaccharide of $C$. neoformans. More recently, the chemical structures of the repeating units of serotypes $\mathrm{A}, \mathrm{C}$ and $\mathrm{D}$ of $C$. neoformans have been demonstrated ${ }^{13 \sim 19)}$. Further studies on the chemical structures responsible for the antigenic specificities of the serotypes of Cryptococcus neoformans and related species remaine to be elucidated.

Our results suggest that the serological, chemical and physicochemical characteristics of soluble capsular polysaccharides would be useful criteria in the classification of the Cryptococcus species, although microheterogeneity is demonstrated in the polysaccharide structures due to episemantic molecules $^{20)}$. For example, C. uniguttulatus was first isolated from a diseased nail by Wolfram and Zach and named Eutorulopsis uniguttulata ${ }^{21}$. Based on the morphological and physiological similarities of this yeast-like fungus to C. neoformans, except for its weak ability to form a capsule, 
Lodder et al. redescribed it as $C$. neoformans var. uniguttulatus $^{22)}$. Kreger-van Rij and Staib suggested that $C$. neoformans var. uniguttulatus should be elevated to the rank of species on the basis of its assimilation pattern and inability to grow at $37^{\circ} \mathrm{C}^{23)}$. In 1970 this variety of $C$. neoformans was raised to the rank of a species ${ }^{10)}$. In 1977, Kwon-Chung discovered the perfect state of $C$. uniguttulatus and named it Filobasidium uniguttula$t_{u m}{ }^{24)}$. Earlier Kwon-Chung discovered the perfect state of Cryptococcus neoformans as a Filobasidiella species $^{25,26)}$. It was placed in a separate genus on the basis of the mechanism of basidiospore formation. These findings support the status of $C$. uniguttulatus as a separate species. Our results, obtained by the characterization of soluble capsular polysaccharides, may support the recent decision to treat $C$. uniguttulatus as a separate species.

In this paper, clinically important Cryptococcus species were studied by the use of only one strain, therefore the differences among strains would have to be taken into consideration. In fact, $C$. neoformans have been shown to be divided into four serotypes. Further characterization of the polysaccharides of $C$. neoformans serotypes A, $\mathrm{B}, \mathrm{C}$ and D as well as those of the other Cryptococcus species are in progress in our laboratory.

\section{ACKNOWLEDGEMENTS}

We are grateful to Dr. L. Ajellc and Dr. E. Reiss, Center for Disease Control, Atlanta, Georgia, for their critical reading of the manuscript and valuable comments and suggestions. We also appreciate the help of Dr. T. Miyazawa and Dr. H. Inagaki, Faculty of Science University of Tokyo, in performing the PMR spectral analyses.

\section{REFERENCES}

1) Tsuchiya, T., Fukazawa, Y. and Kawakita, S.: Significance of serological studies on yeasts. Mycopathol., 26: 1-15, 1965.

2) Tsuchiya, T., Fukazawa, Y., Taguchi, M., Nakase, T. and Sinoda, T.: Serologic aspects on yeast classification. Mycopathol. Mycol. Appl., 53: $77-91,1974$.

3) Gorin, P.A.J. and Spencer, J.F.T.: Proton magnetic resonance spectroscopy-An aid in identification and chemotaxonomy of yeasts. Adv. Appl. Microbiol., 13: 25-89, 1970.

4) Seeliger, H.P.R.: Use of a urease test for the screening and identification of cryptococci. J. Bacteriol., 72: 127-131, 1956.

5) Kozel, T.R. and Cazin, J.: Immune response to Cryptococcus neoformans soluble polysaccharide I. Serological assay for antigen and antibody. Infect. Immun., 5: 35-41, 1972.

6) Lowry, O.H., Rosebrough, N.J., Farr, A.L. and Randall, R.J.: Protein measurement with the Folin phenol reagent. J. Biol. Chem., 193: 265275, 1951.

7) Dubois, M., Gillers, K.A., Hamilton, J.K., Rebers, P.A. and Smith, F.: Colorimetric method for determination of sugars and related substances. Anal. Chem., 28: 350-356, 1956.

8) Gorin, P.A.J. and Spencer, J.F.T.: Galactomannans of Trichosporon fermentans and other yeasts; Proton magnetic resonance and chemical studies. Can. J. Chem., 46: 2299-2304, 1968.

9) Bitter, T. and Muir, H.M.: A modified uronic acid carbazole reaction. Anal. Biochem., 4: 330 334, 1962.

10) Phaff, H.J. and Fell, J.W.: Cryptococcus Kützing emend. Phaff et Spencer. In The yeasts, a taxonomic study. (Lodder, J. ed.), p. 1088-1145, North Holland Publ. Co., Amsterdam, 1970.

11) Fukazawa, Y., Nishikawa, A., Suzuki, M. and Shinoda, T.: Immunochemical basis of the serclogic specificity of the yeast: Immunochemical determinants of several antigenic factors of yeasts. Medical Mycology, Zbl. Bakt. Suppl., 8: 128$136,1980$.

12) Fukazawa, Y., Nakase, T., Shinoda, T., Kagaya, K. and Nishikawa, A.: Immunological specificity of capsular polysaccharide of Cryptococcus neoformans. Proceedings of the 4th International symposium on yeasts, Vienna, Austria, 273-274, 1974.

13) Miyazaki, T.: Fungal polysaccharides. I. Isolation and chemical properties of capsular polysaccharide from Cryptococcus neoformans. Chem. Pharm. Bull., 9: 715-718, 1961.

14) Miyazaki, T.: Fungal polysaccharides. II. The component sugars and partial hydrolysis of the capsular polysaccharide from Cryptococcus neoformans. Chem. Pharm. Bull., 9: 826-829, 1961.

15) Miyazaki, T.: Fungal polysaccharides. III. Chemical structure of the capsular polysaccharide from Cryptococcus neoformans. Chem. Pharm. Bull., 9: $829-833,1961$.

16) Bhattacharjee, A.K., Kwon-Chung, K.J. and Glaudemans, C.P.J.: On the structure of the capsular polysaccharide from Cryptococcus neoformans serotype C. Immunochem., 15: 673-679, 1978. 
17) Bhattacharjee, A.K., Kwon-Chung, K.J. and Glaudemans, C.P.J.: On the structure of the capsular polysaccharide from Cryptococcus neoformans serotype C-II. Mol. Immunol., 16: 531532, 1979.

18) Bhattacharjee, A.K., Kwon-Chung, K.J. and Glaudemans, C.P.J.: The structure of the capsular polysaccharide from Cryptococcus neoformans serotype D. Carbohydr. Res., 73: 183192, 1979.

19) Cherniak, R., Reiss, E., Slodki, M.E., Plattner, R.D. and Blumer, S.O.: Structure and antigenic activity of the capsular polysaccharide of Cryptococcus neoformans serotype A. Mol. Immunol., 17: 1025-1032, 1980.

20) Zucherkandl, E. and Pauling, L.: Molecules as documents of evolutionary history. J. Theoret. Biol., 8: 357-366, 1965.

21) Wolfram, S. and Zach, F.: Über durch niedere
Pilze verursachte Nagelerkrankungen beim Menschen. Arch. Dermatol. Syphilis., 170: 681-6e4, 1934.

22) Lodder, J. and N.J.W. Kreger-van Rij. In The yeasts, a taxonomic study. North Holland Publ. Co., Amsterdam, 1952.

23) Kreger-van Rij, N.J.W.: Taxonomy of Cryptococcus neoformans and its variety uniguttulatus. Antonie van Leeuwenhoek J. Microbiol. Serol., 27: 59-64, 1961.

24) Kwon-Chung, K.J.: Perfect state of Cryptococcus uniguttulatus. Int. J. Syst. Bacteriol., 27: 293299, 1977.

25) Kwon-Chung, K.J.: A new Genus, Filobasidiella, the sexual state of Cryptococcus neoformans. Mycologia, 67: 1197-1200, 1975.

26) Kwon-Chung, K.J.: A new species of Filobasidiella, the sexual state of Cryptococcus neoformans $\mathrm{B}$ and $\mathrm{C}$ serotypes. Mycologia, 68: 942—946, 1976. 